\title{
Subcutaneous Panniculitis-Like T-Cell Lymphoma (SPTL) in a Child with Spontaneous Resolution
}

\author{
Achiléa L. Bittencourt, ${ }^{1}$ Maria das Graças Silva Vieira, ${ }^{1}$ Eny Guimarães Carvalho, ${ }^{2}$ \\ Celeste Cunha, ${ }^{2}$ and Iguaracyra Araujo ${ }^{1}$ \\ ${ }^{1}$ Department of Pathology, Complexo Hospitalar Universitário Prof. Edgard Santos, Federal University of Bahia, Salvador, BA, Brazil \\ ${ }^{2}$ Oncology Department, Pediatric Hospital Martagão Gesteira, Liga Baiana Contra a Mortalidade Infantil, Salvador, BA, Brazil
}

Correspondence should be addressed to Achiléa L. Bittencourt, achilea@uol.com.br

Received 28 July 2011; Accepted 12 September 2011

Academic Editors: T. Arkenau, M. W. Bekkenk, and M. Mosunjac

Copyright (C) 2011 Achiléa L. Bittencourt et al. This is an open access article distributed under the Creative Commons Attribution License, which permits unrestricted use, distribution, and reproduction in any medium, provided the original work is properly cited.

\begin{abstract}
Subcutaneous panniculitis-like T-cell lymphomas (SPTLs) $\alpha / \beta$ are rare in childhood. The present report refers to a case of a 7-yearold male child presenting an extensive skin lesion that began when he was 5 years of age. Two biopsies were evaluated using the $\mathrm{CD} 3, \mathrm{CD} 4, \mathrm{CD} 8, \mathrm{CD} 56, \beta \mathrm{F} 1$, and TIA markers. A dense infiltrate of CD3+, CD4-, CD8+, CD56-, $\beta \mathrm{F} 1+$, and TIA+ pleomorphic lymphocytes was found in the subcutis. The previous biopsy showed cytophagic histiocytic panniculitis with a small focus on $\mathrm{CD} 8+$ and $\beta \mathrm{F} 1+$ malignant cells. The lesion regressed spontaneously. This case shows that prognosis may be excellent in SPTL $(\alpha / \beta)$. On the other hand, it also serves as an alert that a biopsy performed in an area of cytophagic panniculitis may lead to misdiagnosis.
\end{abstract}

\section{Introduction}

Subcutaneous panniculitis-like T-cell lymphoma (SPTL) was described in 1992 [1] as a new type of cutaneous Tcell lymphoma mimicking panniculitis. SPTL was subsequently included in the World Health Organization (WHO)'s classification of hematopoietic and lymphoid tissues as a tumor of either $\alpha / \beta$ or $\gamma / \delta$ cytotoxic T-cell phenotype [2]. However, in the latest $\mathrm{WHO} /$ European Organization for Research and Treatment of Cancer (EORTC) classification of primary cutaneous lymphomas, only SPTLs expressing an $\alpha / \beta$ phenotype were referred to as SPTL, whereas cases with a $\gamma / \delta$ phenotype were included in the group of peripheral T-cell lymphomas, unspecified, referred to as cutaneous $\gamma / \delta$ T-cell lymphomas ( $\mathrm{C} \gamma / \delta$-TCLs) [3].

Recently, the EORTC Cutaneous Lymphoma Study Group has evaluated 63 cases of SPTL and 20 cases of $C \gamma / \delta$ TCLs and showed clear differences between the $\alpha / \beta$ and $\gamma / \delta$ phenotypes. While the 5 -year overall survival rate in cases of SPTL $(\alpha / \beta)$ is generally around $82 \%$, with $\mathrm{C} / \delta$-TCL, the 5 year overall survival rate is $11 \%[4]$.
The objective of this paper was to describe an unusual case of SPTL $(\alpha / \beta)$ occurring in a child in whom involution was spontaneous.

\section{Case Summary}

A 7-year-old male Brazilian child presented an extensive skin lesion that began when he was 5 years of age associated with constant fever varying from 38 to $39^{\circ} \mathrm{C}$. The patient was HTLV-1 negative and HIV negative. Dermatological examination revealed diffuse erythema and infiltration of the skin involving the infraumbilical area and right inguinal region extending to the anterior and internal surfaces of the upper two-thirds of his right thigh (Figure 1). Routine laboratory tests revealed only mild anemia. The patient underwent one biopsy of the lesion which resulted in diagnoses of chronic panniculitis. Four months later, another biopsy was performed, and a diagnosis of SPTL $(\alpha / \beta)$ was made. The previous biopsy was reviewed. Anatomopathological and immunohistochemical studies. A dense and diffuse infiltrate of small and medium-sized lymphocytes with nuclear contour 


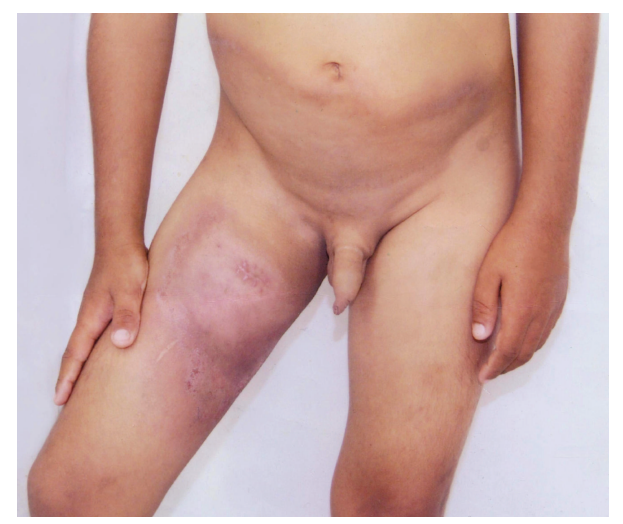

FIGURE 1: Extensive erythematous infiltrated plaque involving the abdomen and the right tight.

irregularity was found confined to the subcutaneous tissue. Rimming of the neoplastic cells surrounding individual fat cells was frequently found (Figure 2(a)). Many admixed histiocytes, small granulomas, and few foci with karyorrhectic debris were seen. Alcian blue staining revealed no mucin deposition. The neoplastic cells were $\mathrm{CD} 2+$, $\mathrm{CD} 3+, \mathrm{CD} 4-, \mathrm{CD} 7+, \mathrm{CD} 8+$ (Figure 2(b)), CD20-, CD30-, UCHL-1+, CD56-, CD79-, $\beta$ F1+ (Figure 2(c)), and TIA+. Many CD68+ cells were seen amidst the neoplastic cells. The proliferative index (Ki-67) was 40\% (Figure 2(d)). Diagnosis was SPTL $(\alpha / \beta)$. Review of the previous biopsy then revealed vacuolated histiocytes and epithelioid cells, with few lymphocytes in the fat lobules. Only a small, peripheral focus of interstitial infiltration of malignant lymphocytes $\mathrm{CD} 3+, \mathrm{CD} 8+$, and $\beta \mathrm{F} 1+$ was found. Taking the diagnosis of the latest biopsy into account, this was then considered to constitute a case of SPTL $(\alpha / \beta)$ admixed with a cytophagic histiocytic panniculitis. Evolution. In the seven months that it took to reach a conclusive diagnosis, during which no treatment was given, the patient underwent a progressive and accentuated reduction in infiltration. After the definitive diagnosis, he was submitted to the following staging investigations, all of which were normal, complete blood cell count, blood chemistry panel, chest radiography, computed tomography scan of the chest and upper and lower abdomen, and bone scintigraphy. There was no evidence of T-cell infiltrate or hemophagocytosis in the bone marrow smear or biopsy specimen. It was decided not to treat the patient. Examination of the patient four months later, showed only pigmentation of the skin at the site of the lesion. At the latest follow-up visit 20 months later, the patient continued in full remission.

\section{Discussion}

SPTL $(\alpha / \beta)$ affects a younger age group than $C \gamma / \delta$-TCL, the median age of patients being 36 years of age. This is a rare type of lymphoma; however, many cases of SPTL $(\alpha / \beta)$ may be overlooked and may have been misdiagnosed as panniculitis [4]. Weenig et al. [5] described an adult case in which diagnosis was only possible after the eighth biopsy.

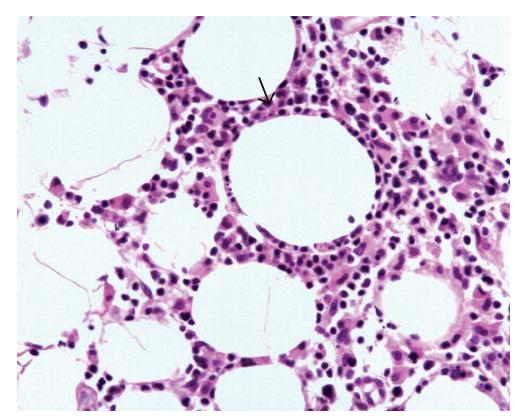

(a)

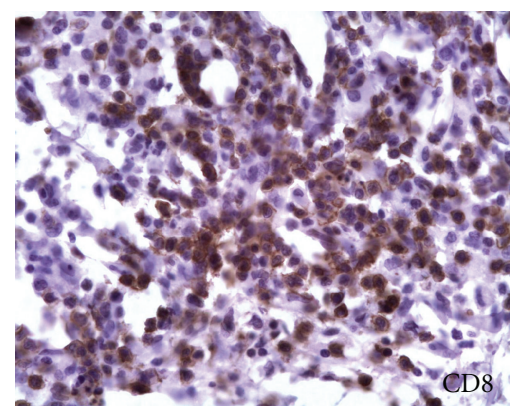

(b)

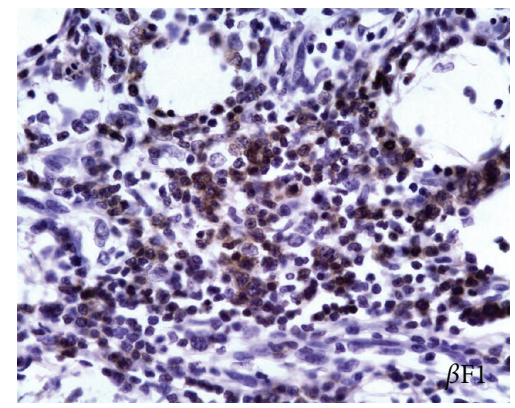

(c)

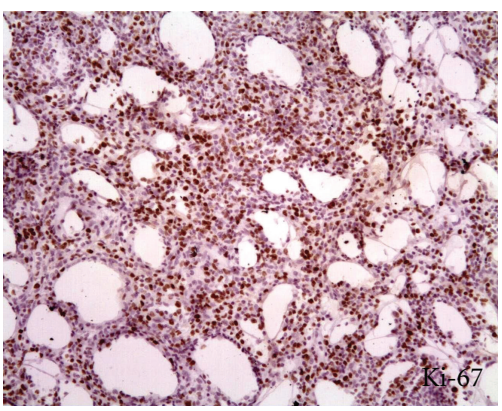

(d)

Figure 2: (a) Diffuse infiltration of small- and medium-sized pleomorphic lymphocytes is seen between the fat cells with rimming of the neoplastic cells around one individual fat cell (arrow) $(\mathrm{H} \& \mathrm{E}$ stain; original magnification $\times 320)$. (b) CD8 positivity of the neoplastic cells (original magnification $\times 400$ ). (c) The majority of the cells presents the $\alpha \beta$ phenotype ( $\beta \mathrm{F} 1$, original magnification $\times 640$ ). (d) A high proliferative index of the malignant cells is observed $($ Ki-67, original magnification $\times 125)$.

In the case reported here, after reviewing the previous biopsy, a pattern of cytophagic histiocytic panniculitis was found, with one small, peripheral area containing atypical CD8+, 
CD56-, and $\beta \mathrm{F} 1+$ lymphocytes, confirming that this biopsy indeed corresponded to a case of SPTL $(\alpha / \beta)$.

It is impossible to be sure whether the observed panniculitis consists in fact of areas of involution of the tumor or whether it is rather a case of SPTL that has developed from cytophagic histiocytic panniculitis (CHP). According to Marzano et al. [6], CHP may progress to SPTL. However, considering that the lesion regressed progressively until its disappearance, it is more likely that CHP represents involution of the tumor.

In many studies reported in the literature that include children and adolescents, no differentiation was made between the $\alpha / \beta$ and $\gamma / \delta$ phenotypes [7-12]. On the other hand, in the few studies that included children and adolescents as well as adults and in which differentiation was made between these two phenotypes, the cases were not studied individually; therefore, it was impossible to obtain clinicopathological data on younger patients $[13,14]$. There are few cases of SPTL $(\alpha / \beta)$ in children and adolescents of 18 years of age or less in which a differential diagnosis was performed with cutaneous $\gamma / \delta$ T-cell lymphomas by immunohistochemistry or by molecular biology [15-20]. These patients ranged from 6 months to 18 years of age. Clinically, the lesions appeared in the form of nodules or plaques. Four patients had systemic disease, two with hemophagocytic syndrome $[15,17]$. In three cases, complete regression of the disease occurred following treatment, which consisted of chemotherapy in two cases $[15,16]$ and oral steroids in the remaining case [20]. Nevertheless, three deaths occurred, all in patients with systemic disease, which was associated in one case with hemophagocytic syndrome $[15,17]$. In two cases, there was no reference to clinical characteristics, treatment, or outcome $[18,19]$. Further studies involving a greater number of cases would be required to evaluate whether the disease behaves differently in children and adolescents compared to adults.

The present case was diagnosed as SPTL $(\alpha / \beta)$ rather than $\mathrm{C} \gamma / \delta$-TCL because of the clinical, anatomopathological, and immunohistochemical features present. The confinement of the infiltrate to the subcutaneous tissue, as observed in the present case, constitutes a feature that is helpful in the diagnosis of SPTL $(\alpha / \beta)$. Furthermore, unlike cases of $\mathrm{C} \gamma / \delta$ TCL, the malignant cells were CD4-, CD8+, CD56-, and $\beta \mathrm{F} 1+[4]$.

It is believed that some cases, originally diagnosed as lupus erythematosus profundus (LEP), may indeed have consisted of cases of SPTL $(\alpha / \beta)[4,5]$. Important clues to distinguish SPTL $(\alpha / \beta)$ from LED include epidermal involvement, interphase dermatitis, mucin deposition, and the presence of clusters of B cells or admixed plasma cells and reactive germinal centers $[4,21]$.

Considering that in the present case there was spontaneous involution of the disease, it is important to make a differential diagnosis with atypical lymphocytic lobular panniculitis (ALLP), a condition considered to represent a preneoplastic phase of SPTL $(\alpha / \beta)$, characterized by a subcutaneous lesion with a waxing and waning course. Some distinguishing morphological features are present in ALLP including the absence of a greater density of infiltration, a much lesser degree of cytologic lymphoid atypia, a low proliferative index, the presence of a significant number of CD4+ lymphocytes, and lack of $\beta \mathrm{F} 1$ expression [21]. In addition, interstitial mucin deposition is a characteristic feature of ALLP, and the striking dominance of CD8+ cells that typifies cases of SPTL $(\alpha / \beta)$ is absent [21]. According to Magro et al. (2007) [21], there are insufficient lymphoid atypia in ALLP for a diagnosis of lymphoma. Unlike the majority of SPTL $(\alpha / \beta)$ cases in the literature, complete spontaneous resolution of the lesion occurred in the present case with no further treatment. Spontaneous involution of this disease has been previously observed in only two of the 63 cases recently reviewed in the literature [4].

\section{Conclusion}

The current case shows that prognosis may be excellent with this form of lymphoma. On the other hand, it also serves as an alert that a biopsy performed in an area of cytophagic panniculitis may lead to misdiagnosis, hence, the importance of continued followup with repeated biopsies when SPTL $(\alpha / \beta)$ is suspected. A differential diagnosis between SPTL $(\alpha / \beta)$ and $\mathrm{C} \gamma / \delta$-TCL must be performed in all pediatric cases, and all cases of SPTL $(\alpha / \beta)$ should be published in order to provide pediatric oncologists with more complete and exact data on the morbidity and therapeutic management of this disease.

\section{Acknowledgments}

The authors are grateful to Dr Helena Muller who provided the paraffin block of the first biopsy of this case. This work was supported by Conselho Nacional de Pesquisa (CNPq) and Fundação de Apoio à Pesquisa no Estado da Bahia (FAPESB).

\section{References}

[1] C. L. Gonzalez, L. J. Medeiros, R. M. Braziel, and E. S. Jaffe, "T-cell lymphoma involving subcutaneous tissue: a clinicopathologic entity commonly associated with hemophagocytic syndrome," American Journal of Surgical Pathology, vol. 15, no. 1, pp. 17-27, 1991.

[2] E. S. Jaffe and E. Ralfkiaer, "Subcutaneous panniculitis-like TCell lymphoma," in World Health Organization Classification of Tumours: Pathology and Genetics of Tumours of Haematopoietic and Lymphoid Tissues, E. S. Jaffe, N. Harris, H. Stein, and J. W. Vardiman, Eds., pp. 212-213, IARC, Lyon, France, 2001.

[3] G. Burg, W. Kempf, A. Cozzio et al., "WHO/EORTC classification of cutaneous lymphomas 2005: histological and molecular aspects," Journal of Cutaneous Pathology, vol. 32, no. 10, pp. 647-674, 2005.

[4] R. Willemze, P. M. Jansen, L. Cerroni et al., "Subcutaneous panniculitis-like T-cell lymphoma: definition, classification, and prognostic factors: an EORTC Cutaneous Lymphoma Group Study of 83 cases," Blood, vol. 111, no. 2, pp. 838-845, 2008.

[5] R. H. Weenig, C. S. Ng, and C. Perniciaro, "Subcutaneous panniculitis-like T-cell lymphoma: an elusive case presenting as lipomembranous panniculitis and a review of 72 cases in 
the literature," American Journal of Dermatopathology, vol. 23, no. 3, pp. 206-215, 2001.

[6] A. V. Marzano, E. Berti, M. Paulli, and R. Caputo, "Cytophagic histiocytic panniculitis and subcutaneous panniculitis-like Tcell lymphoma: report of 7 cases," Archives of Dermatology, vol. 136, no. 7, pp. 889-896, 2000.

[7] S. K. Ali, N. M. Othman, A. B. Tagoe, and A. A. Tulba, "Subcutaneous panniculitic $\mathrm{T}$ cell lymphoma mimicking histiocytic cytophagic panniculitis in a child," Saudi Medical Journal, vol. 21, no. 11, pp. 1074-1077, 2000.

[8] R. E. Hutchison, J. H. Laver, M. Chang, T. Muzzafar, S. Desai, and S. Murphy, "Non-anaplastic peripheral T-cell lymphoma in childhood and adolescence: a children's oncology group study," Pediatric Blood and Cancer, vol. 51, no. 1, pp. 29-33, 2008.

[9] G. Y. Lim, S. T. Hahn, N. G. Chung, and H. K. Kim, "Subcutaneous panniculitis-like T-cell lymphoma in a child: whole-body MRI in the initial and follow-up evaluations," Pediatric Radiology, vol. 39, no. 1, pp. 57-61, 2009.

[10] R. S. Paschoal, R. N. Cardilli, D. Arruda, B. P. Simões, and C. D. S. Souza, "Subcutaneous panniculitis-like T-cell lymphoma," Anais Brasileiros de Dermatologia, vol. 84, no. 4, pp. 415-419, 2009.

[11] L. Rajić, E. Bilić, R. Femenić et al., "Subcutaneous panniculitis-like T-cell lymphoma in a 19 month-old boy: a case report," Collegium Antropologicum, vol. 34, no. 2, pp. 679-682, 2010.

[12] R. Kobayashi, K. Yamato, F. Tanaka et al., "Retrospective analysis of non-anaplastic peripheral T-cell lymphoma in pediatric patients in Japan," Pediatric Blood and Cancer, vol. 54, no. 2, pp. 212-215, 2010.

[13] R. S. Go and S. M. Wester, "Immunophenotypic and molecular features, clinical outcomes, treatments, and prognostic factors associated with subcutaneous panniculitis-like T-cell lymphoma: a systematic analysis of 156 patients reported in the literature," Cancer, vol. 101, no. 6, pp. 1404-1413, 2004.

[14] Y. Y. Kong, B. Dai, J. C. Kong et al., "Subcutaneous panniculitis-like T-cell lymphoma: a clinicopathologic, lmmunophenotypic, and molecular study of 22 Asian cases according to WHO-EORTC classification," American Journal of Surgical Pathology, vol. 32, no. 10, pp. 1495-1502, 2008.

[15] M. J. A. Koh, S. P. Sadarangani, Y. C. Chan et al., "Aggressive subcutaneous panniculitis-like T-cell lymphoma with hemophagocytosis in two children (subcutaneous panniculitis-like T-cell lymphoma)," Journal of the American Academy of Dermatology, vol. 61, no. 5, pp. 875-881, 2009.

[16] K. E. Salhany, W. R. Macon, J. K. Choi et al., "Subcutaneous panniculitis-like T-cell lymphoma. Clinicopathologic, immunophenotypic, and genotypic analysis of alpha/beta and gamma/delta subtypes," American Journal of Surgical Pathology, vol. 22, no. 7, pp. 881-893, 1998.

[17] A. V. Marzano, E. Berti, M. Paulli, and R. Caputo, "Cytophagic histiocytic panniculitis and subcutaneous panniculitis-like Tcell lymphoma: report of 7 cases," Archives of Dermatology, vol. 136, no. 7, pp. 889-896, 2000.

[18] C. Massone, A. Chott, D. Metze et al., "Subcutaneous, blastic natural killer (NK), NK/T-cell, and other cytotoxic lymphomas of the skin: a morphologic, immunophenotypic, and molecular study of 50 patients," American Journal of Surgical Pathology, vol. 28, no. 6, pp. 719-735, 2004.

[19] S. Kumar, L. Krenacs, J. Medeiros et al., "Subcutaneous panniculitic T-cell lymphoma is a tumor of cytotoxic $t$ lymphocytes," Human Pathology, vol. 29, no. 4, pp. 397-403, 1998.
[20] H. Briki, J. D. Bouaziz, V. Molinier-Frenkel et al., "Subcutaneous panniculitis-like $\mathrm{T}$ cell lymphoma alphabeta: complete sustained remission with corticosteroids and methotrexate," British Journal of Dermatology, vol. 163, no. 5, pp. 1136-1138, 2010.

[21] C. M. Magro, J. Guitart, and A. N. Crowson, "Precursor lesions of cutaneous T-cell lymphoma," in The Cutaneous Lymphoid Proliferations, C. M. Magro, A. N. Crowson, and M. C. Mihm Jr., Eds., pp. 93-140, Wiley-Liss, New Jersey, NJ, USA, 2007. 


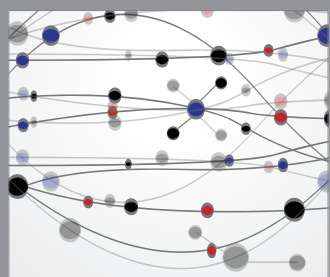

The Scientific World Journal
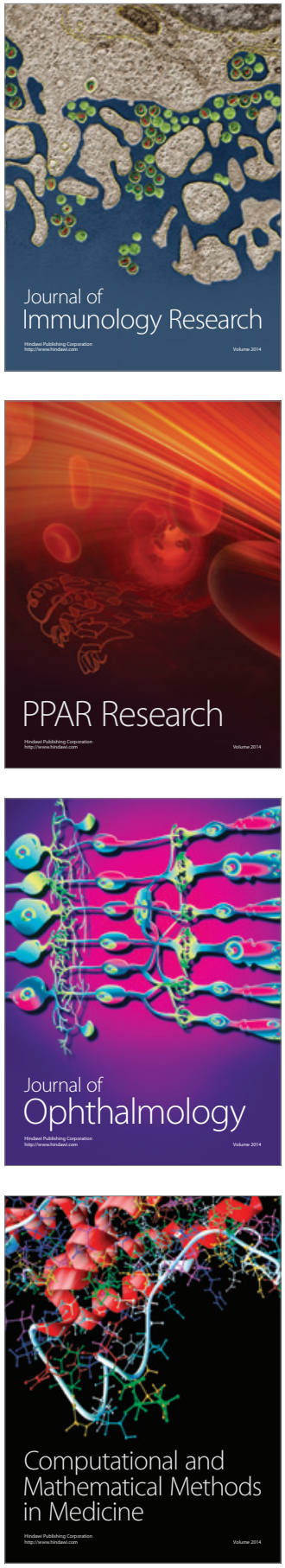

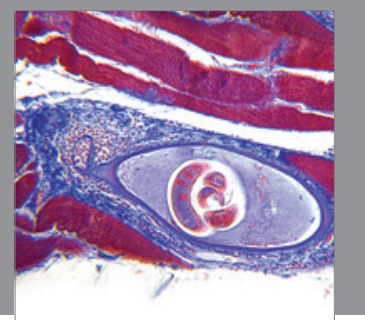

Gastroenterology

Research and Practice
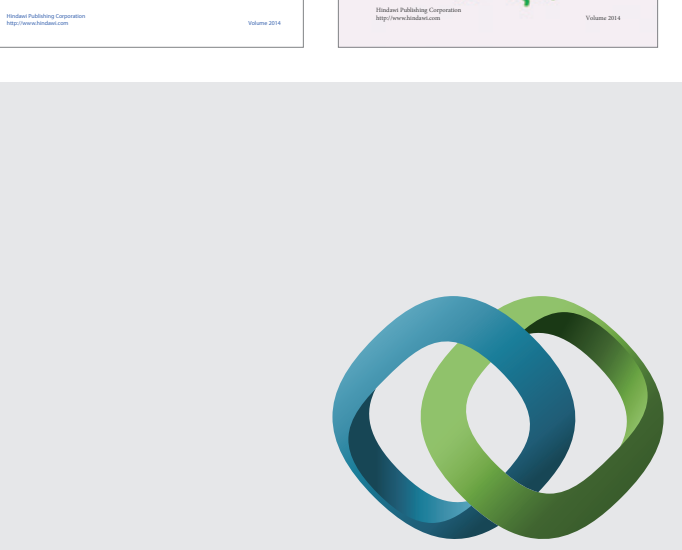

\section{Hindawi}

Submit your manuscripts at

http://www.hindawi.com
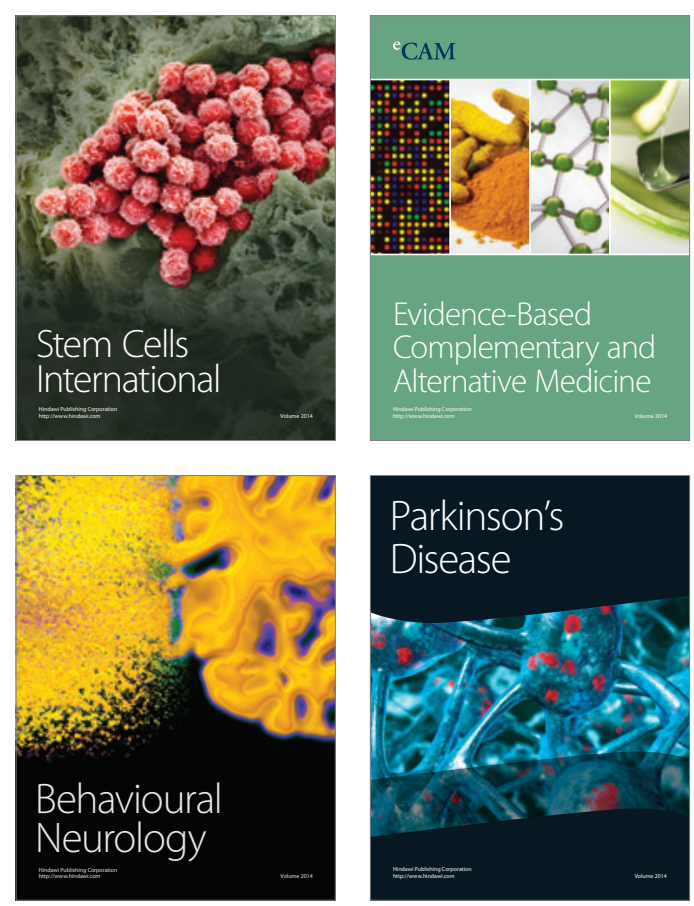

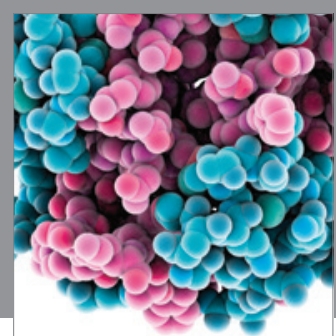

Journal of
Diabetes Research

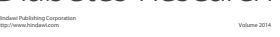

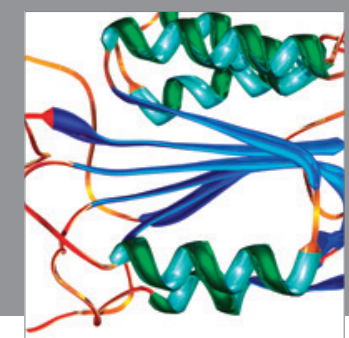

Disease Markers
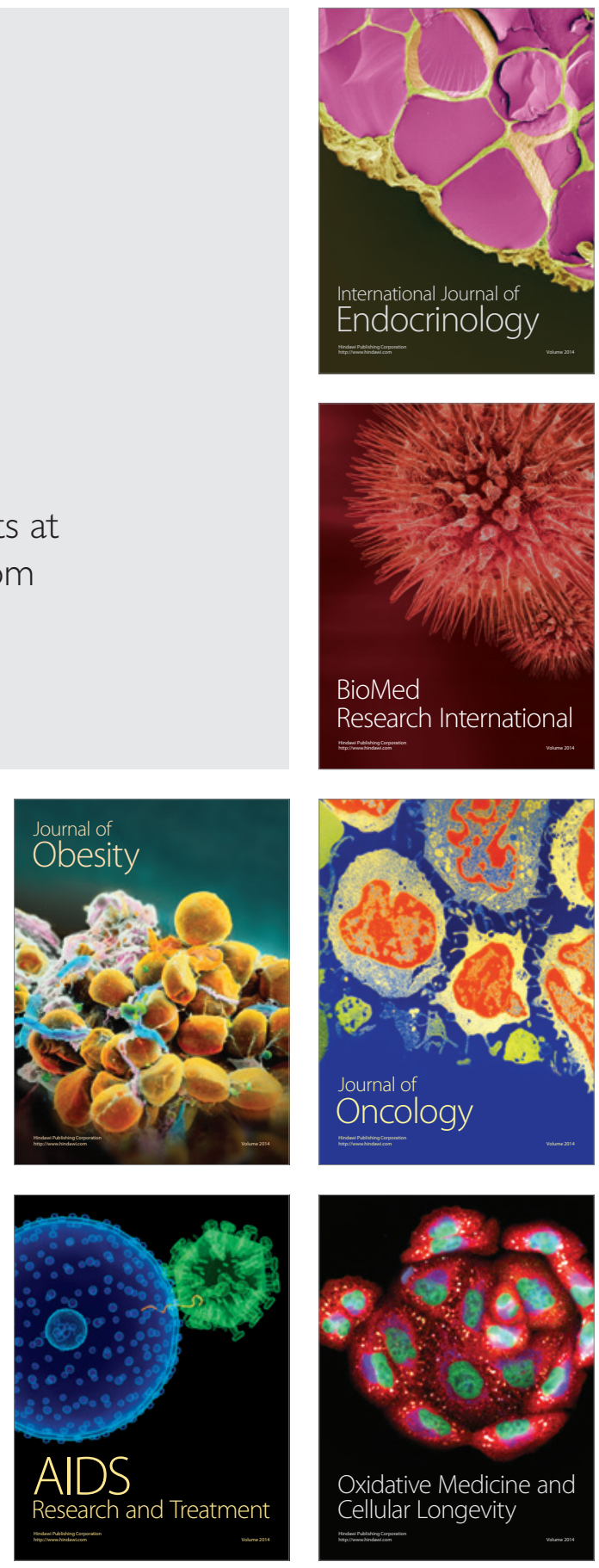